\title{
Cellular interaction of the smut fungus Ustacystis waldsteiniae 1
}

\author{
Robert Bauer, Kurt Mendgen, and Franz Oberwinkler
}

\begin{abstract}
The cellular interaction between the smut fungus Ustacystis waldsteiniae and its host Waldsteinia geoides was analyzed by serial-section electron microscopy using chemically fixed and high-pressure frozen - freeze-substituted samples. After penetration, each haustorium extends a short distance into the host cell where it often forms up to three short lobes. The haustorium is wholly ensheathed by a prominent matrix. The matrix is a complex structure, differing significantly from that known of other fungal plant parasites: it is filled with amorphous, electron-opaque material in which membrane-bounded, coralloid vesicles are embedded. During the contact phase of the hypha with the host cell wall, vesicles with electron-opaque contents accumulate in the contact area of the hypha where they appear to fuse with the fungal plasma membrane and extrude their contents. Subsequently, the host cell wall increases in electron opacity and matrix material becomes deposited between host plasma membrane and host cell wall exactly at the ends of the altered areas in the host cell wall. The coralloid vesicles within the matrix, however, are of host origin: exocytosis of Golgi products into the matrix results in the formation of coralloid vesicular buds in the host plasma membrane. Subsequently, the buds seem to detach from the host plasma membrane to flow as coralloid vesicles into the matrix. Matrix development continues during penetration and after penetration at the haustorial tips. After host wall penetration, the fungal cell wall comes in contact with the matrix. The fungal component of the matrix may play a key role in the inducement of these transfer cell-like compartments in host cells responding to infection.
\end{abstract}

Key words: freeze substitution, haustoria, high-pressure freezing, host-parasite interaction, smut fungi, Ustacystis waldsteiniae.

Résumé : L'interaction cellulaire entre le champignon du charbon Ustacystis waldsteiniae et son hôte, le Waldsteinia geoides a été analysée en microscopie électronique sur sections sériées et en utilisant des échantillons fixés chimiquement ou cryo-substitués sous haute pression. Après la pénétration, l'haustérie s'étend sur une courte distance dans la cellule de l'hôte où il forme souvent jusqu'à trois lobes. L'haustérie est totalement enveloppée dans une matrice bien visible. La matrice est une structure complexe, différent significativement dè celle qu'on connait chez d'autres parasites fongiques des plantes; il est rempli d'un matériel amorphe opaque aux électrons dans lequel baignent des vésicules coralloïdes enveloppées dans une membrane. Au cours de la phase de contact des hyphes avec la paroi de la cellule hôte, les vésicules avec des contenus opaques aux électrons s'accumulent dans la région de contact des hyphes, où ils semblent se fusionner avec la plasmalemme fongique et expulser leurs contenus. Subséquemment, l'opacité aux électrons de la paroi de la cellule hôte augmente et le matériel matriciel se retrouve entre la plasmalemme de l'hôte et la paroi cellulaire de l'hôte, exactement aux extrémités des surfaces altérées de la paroi cellulaire de l'hôte. Les vésicules corallö̈des de la matrice, appartiennent cependant à l'hôte : l'exocytose de produits de l'appareil de Golgi dans la matrice conduit à la formation de bourgeons sur les vésicules corallö̈des, dans la plasmalemme de l'hôte. Subséquemment les bourgeons semblent se détacher de la plasmalemme de l'hôte pour s'épancher sous forme de vésicules coralloïdes dans la matrice. Le développement de la matrice se poursuit au cours de la pénétration des bouts des haustéries. Après la pénétration de la paroi cellulaire de l'hôte, la paroi cellulaire fongique vient en contact avec la matrice. La composante fongique de la matrice pourrait jouer un rôle clé dans le déclenchement de la formation de ces compartiments de transfert ressemblant à des cellules, chez les cellules hôtes, en réaction à l'infection.

Mots clés : cryo-substitution, haustéries, congélation sous haute pression, interaction hôte-parasite, champignons du charbon, Ustacystis waldsteiniae.

[Traduit par la rédaction]

R. Bauer ${ }^{2}$ and F. Oberwinkler. Universität Tübingen, Institut für Biologie I, Lehrstuhl Spezielle Botanik und Mykologie, Auf der Morgenstelle 1, D-72076 Tübingen, Germany.

K. Mendgen. Universität Konstanz, Fakultät für Biologie, Lehrstuhl für Phytopathologie, Universitätsstrasse 10, D-78434 Konstanz, Germany.

Part 110 of the series Studies in Heterobasidiomycetes from the Botanical Institute, University of Tübingen.

Author to whom all correspondence should be addressed. 
Figs. 1-4. Haustoria prepared by conventional fixation (Figs. 1 and 3) or freeze substitution (Figs. 2, 4). Scale bars $=1 \mu \mathrm{m}$. Fig. 1. Section showing a conventionally fixed haustorium $(h)$ with two sectioned lobes $(l)$. The haustorium is continuous with its intercellular hypha $(i h)$. The electron-opaque matrix surrounding the haustorium is recognizable (arrowheads). The host nucleus is visible at N. Fig. 2. Presumed young haustorium $(h)$ after freeze substitution illustrated to show the well-preserved cytoplasm of both partners. The membranes are smooth. Note that the matrix (arrowhead) surrounding the haustorium is
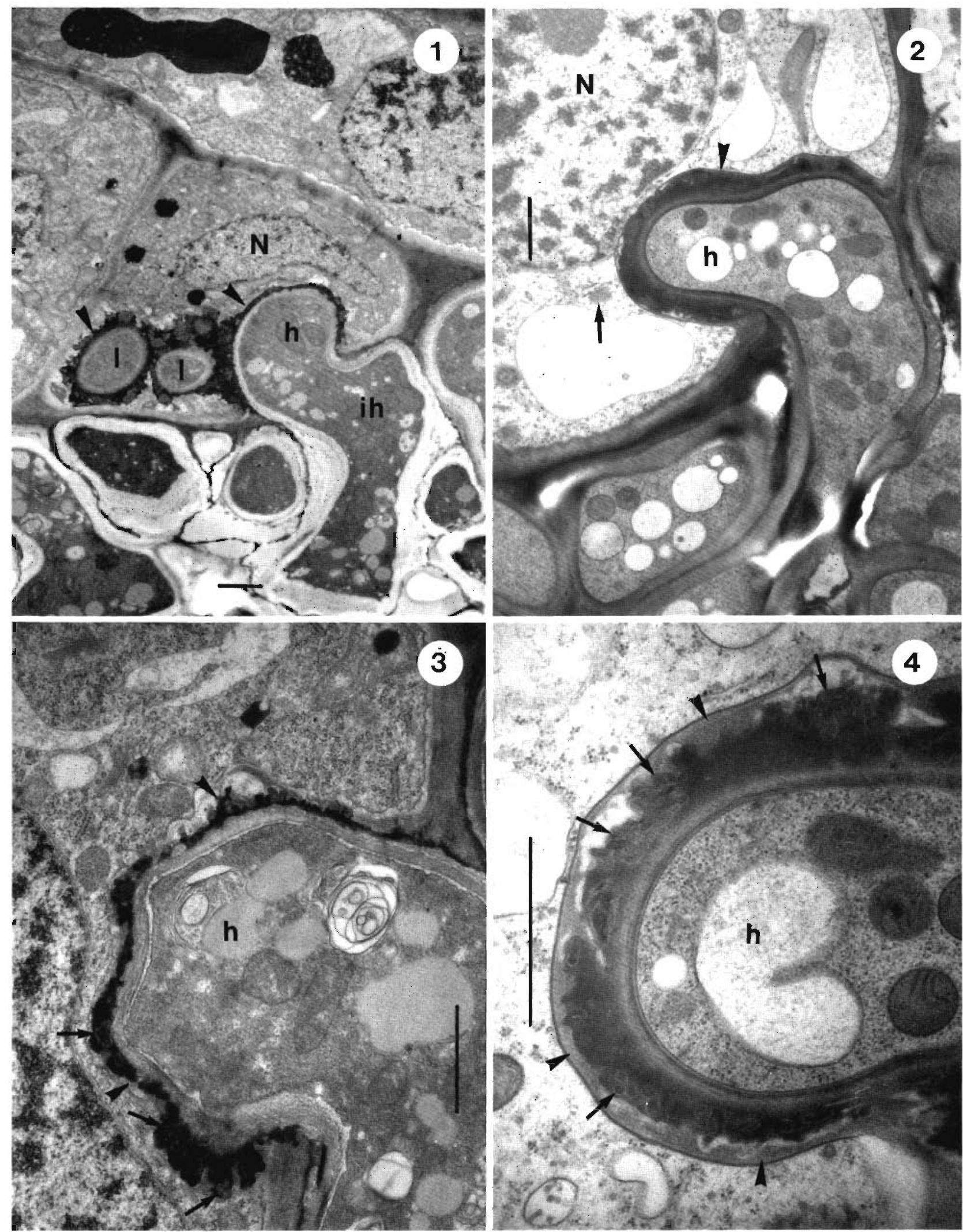
thicker and electron lighter than after conventional fixation. A Golgi body (arrow) is situated next to the matrix. The host nucleus is visible at N. Fig. 3. Section through a conventionally fixed haustorium $(h)$ illustrated to show the irregular shape of the matrix (arrowheads). It is of greater electron opacity than after freeze substitution (compare with Figs. 2, 4). The contours of the matrix vesicles are recognizable (arrows). Two lobes appear in adjacent serial sections. Fig. 4. Haustorium $(h)$ after freeze substitution showing the distribution of the matrix vesicles (arrows) within the matrix. The matrix is encased by appositional material (arrowheads).

\section{Introduction}

Evolutionary trends within the smut fungi and between the smut fungi and other heterobasidiomycetous groups are poorly understood (Oberwinkler 1985; Vánky 1987). Perhaps because many smut fungi are difficult to collect in a suitable condition for electron microscopy and (or) are difficult to fix, few studies of their ultrastructural characteristics are available (Oberwinkler 1985; Bauer et al. 1991). Therefore, during the last 8 years we have examined numerous smut fungi and presumed relatives by electron microscopy. These studies indicate that ultrastructural characteristics of the parasitic interaction are stable and useful for studying natural affinities within the smut fungi.

Here we describe the cellular interaction between the smut fungus Ustacystis waldsteiniae (Peck) Zundel and its host, Waldsteinia geoides Willd. (Rosaceae), based on detailed observations mainly of samples prepared by freeze substitution. Many developmental stages were observed which permit a description of the penetration and infection process.

\section{Materials and methods}

\section{Material}

Ustacystis waldsteiniae on $W$. geoides was collected in the Botanical Garden of the Universität Tübingen, Tübingen, Baden-Württemberg, Germany, April 12, 1991, leg. R: Bauer 1011, April 14, 1992, leg. R. Bauer 1056.

\section{Conventional chemical fixation}

Infected areas of leaves were fixed overnight in $2 \%$ glutaraldehyde in $0.1 \mathrm{M}$ sodium cacodylate buffer ( $\mathrm{pH} 7.2$ ) at room temperature. Following six transfers in $0.1 \mathrm{M}$ sodium cacodylate buffer, samples were postfixed in $1 \%$ osmium tetroxide in the same buffer for $2 \mathrm{~h}$ in the dark, washed in distilled water, and stained in $1 \%$ aqueous uranyl acetate for $1 \mathrm{~h}$ in the dark. After five washes in distilled water, samples were dehydrated in acetone, using 10-min changes at 25, 50, 70, and $95 \%$ acetone and three 10 -min changes in $100 \%$ acetone. Samples were embedded in Spurr's plastic (Spurr 1969).

Serial sections $(65-75 \mathrm{~nm})$ were cut using a Reichert Jung Ultracut E (Leica, Nußloch) equipped with a diamond knife. Sections were mounted on Formvar-coated single-slot copper grids, stained with lead citrate (Reynolds 1963) at room temperature for 3-5 min, and washed again with distilled water. They were examined with a Zeiss EM 109 transmission electron microscope at $80 \mathrm{kV}$.

\section{Freeze substitution}

Infected areas of leaves were removed with a 2-mm cork borer. To remove air from intercellular spaces, samples were infiltrated with distilled water containing 6\% (v/v) $(2.5 \mathrm{M})$ methanol for approximately $5 \mathrm{~min}$ at room temperature.
Single samples were placed in an aluminium holder (one-half with a hollow of $0.3-\mathrm{mm}$ depth for the sample and the other with a flat top) and frozen immediately in the high-pressure freezer HPM 010 (Balzers Union, Lichtenstein) as described in detail by Mendgen et al. (1991).

Substitution medium (1.5 mL per specimen) consisted of $2 \%$ osmium tetroxide in acetone that had been dried over calcium chloride. Freeze substitution was performed at -90 , -60 , and $-30^{\circ} \mathrm{C}, 8 \mathrm{~h}$ for each step, using a Balzers Union FSU 010 freeze-substitution apparatus. The temperature then was raised to approximately $0^{\circ} \mathrm{C}$ over a 30 -min period and samples were washed in dry acetone for another $30 \mathrm{~min}$. Infiltration with an Epon-Araldite mixture (Welters et al. 1988) was performed stepwise: $30 \%$ resin in acetone at $4^{\circ} \mathrm{C}$ for $7 \mathrm{~h}, 70$ and $100 \%$ resin at $8^{\circ} \mathrm{C}$ for $20 \mathrm{~h}$ each, and $100 \%$ resin at $18^{\circ} \mathrm{C}$ for approximately $12 \mathrm{~h}$. Samples were transferred to fresh resin and polymerized at $60^{\circ} \mathrm{C}$ for $10 \mathrm{~h}$.

Samples were processed as for chemically fixed samples described above except that the sections were additionally stained with $1 \%$ aqueous uranyl acetate for $1 \mathrm{~h}$.

\section{Number of investigated interaction sites}

Data for this report were obtained from approximately 300 different interaction sites prepared by freeze substitution, and approximately 70 prepared by chemical fixation.

\section{Results}

\section{General observations}

Examples of conventionally fixed and freeze-substituted interaction stages are shown in Figs. 1, 3, 5, 7, 24-29 and 2, $4,6,9-23$, and $30-49$, respectively. In freeze-substituted samples, details of interaction were in most cases more distinct than those in conventional fixation (compare Fig. 1 with Fig. 2, Fig. 3 with Fig. 4, and Fig. 5 with Fig. 6). Thus, some additional characteristics not seen in material prepared by conventional fixation were visible. A few details, however, were more distinct in conventionally fixed material than in freeze-substituted material. Membranes were generally smoother after freeze substitution than after conventional fixation. In sections of the same thickness, cell walls of both partners were usually more electron opaque after freeze substitution than after conventional fixation (compare Fig. 1 with Fig. 2, and Fig. 5 with Fig. 6). Thick host cell walls appeared generally electron transparent after conventional fixation (Figs. 25-28), but not after freeze substitution (not illustrated).

\section{Infection and haustoria}

Ustacystis waldsteiniae is systemic and probably invades the rhizomes of its host so that new leaves arising from such 
Figs. 5-8. Interfaces between haustoria $(h)$ of Ustacystis waldsteiniae and host cells of Waldsteinia geoides (W in Figs. 5-7) prepared by conventional fixation (Figs. 5, 7) or freeze substitution (Figs. 6, 8). Scale bars $=0.1 \mu \mathrm{m}$. Figs. 5 and 6. Conventionally fixed interface (Fig. 5) and freeze-substituted interface (Fig. 6) with fungal plasma membrane (arrowheads), fungal cell wall $(f w)$, matrix $(m)$, matrix vesicles (V), and extrahaustorial membrane (arrows) for comparison. The matrix is thicker and electron lighter, the enclosed vesicles appear clearer, and the extrahaustorial membrane is much smoother after freeze substitution (Fig. 6) than after conventional fixation (Fig. 5). Note the irregularly folded extrahaustorial membrane in Fig. 5. Fig. 7. Typical appearance of the conventionally fixed matrix vesicles (arrows). The contours of the matrix vesicles are recognizable, but their membranes appear unclear. Fig. 8. Section showing a typical highly branched matrix vesicle after freeze substitution. The tripartite nature of the vesicle membrane appears clear. Note the unequal layering of the fungal plasma membrane (arrowhead).
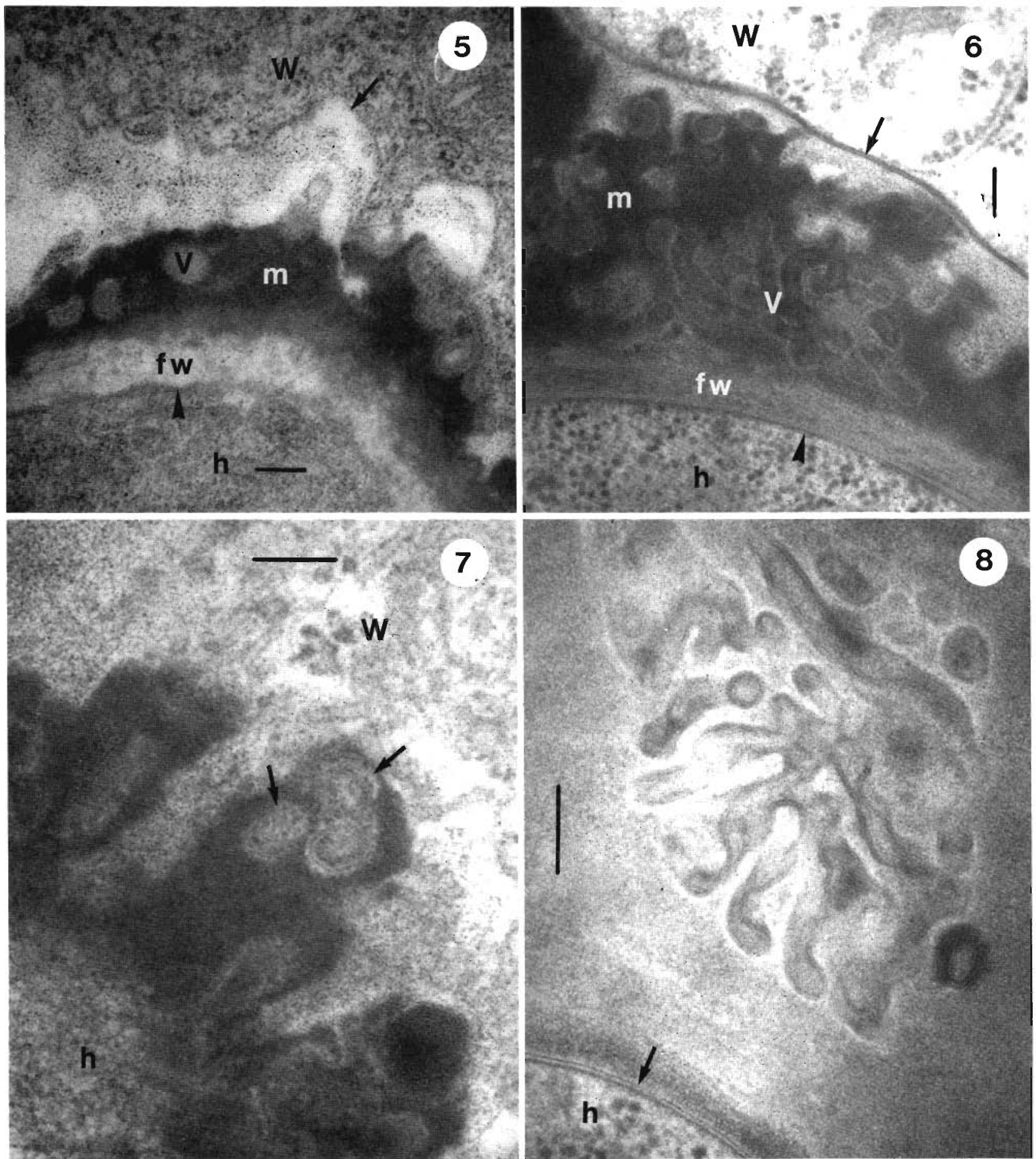
rhizomes are infected. Sori of the smut fungus were formed, however, only on leaves produced in the spring, whereas the leaves produced in the summer and autumn from the same rhizomes did not show any infection. The fungus first appeared in the centre of very young main veins near the leaf margin and caused a significant hypertrophy and an anatomical change of the infected veins; typical vascular elements were not differentiated. Hyphae grew intercellularly in the centre of the altered veins and filled the intercellular spaces in that region nearly completely (Figs. 1,2). Aseptate haustoria (for definition see Bushnell 1972) arose from intercellular hyphal celis that contacted host cells (Figs. 1, 2). Although they were not constricted at the penetration point and specialized structures, such as haustorial mother cells, osmiophilic rings, collars, and papillae were absent (Figs. 1-3), they had a characteristic morphology distinct from intercellular hyphal cells: each haustorium extended a short distance into the host cell where it often formed up to three aseptate short lobes (Fig. 1). It always terminated in the host cell and was surrounded by an extrahaustorial membrane that was continuous with the host plasma membrane (Figs. 2 and 3). More than one haustorium sometimes arose from the same hyphal cell and sometimes these entered different host cells. Several haustoria from different hyphal cells were also observed in a single host cell (not illustrated).

By both fixation techniques the general haustorial architecture was recognizable. In freeze-substituted material, however, haustoria had a more regular appearance and were in most cases more distinct than after conventional fixation (compare Fig. 1 with Fig. 2 and Fig. 3 with Fig. 4). After freeze substitution, the substructure of the host plasma - extrahaustorial membrane appeared different from that of the fungal plasma membrane (compare Fig. 8 with Fig. 12): the two electronopaque layers of the host plasma - extrahaustorial membrane were more or less equal in thickness (Fig. 12). The thickness of each of these layers was comparable with that of the protoplasmic electron-opaque layer of the fungal plasma membrane. The exoplasmic layer of the fungal plasma membrane, however, appeared thinner (Fig. 8).

The most interesting feature of the interaction of Ustacystis waldsteiniae was the prominent and distinct matrix that separated the extrahaustorial membrane from the haustorial cell wall. The matrix was thicker than the haustorial cell wall and exhibited a smooth profile after freeze substitution (Figs. 2, 4,6 ) but not after conventional fixation (Figs. 1, 3, 5). It was composed of amorphous electron-opaque material in which membrane-bounded vesicles were embedded (Figs. 4-7). Electron-transparent lacunae occasionally were distributed throughout the matrix (Figs. 4, 6). The matrix appeared much thicker after freeze substitution than after conventional fixation (compare Fig. 1 with Fig. 2, Fig. 3 with Fig. 4, and Fig. 5 with Fig. 6). In addition, in sections of the same thickness the conventionally fixed matrix was usually of greater electron opacity than the freeze-substituted matrix (compare Fig. 3 with Fig. 4, and Fig. 5 with Fig. 6).

After freeze substitution, the extrahaustorial membrane was generally smooth in the regions of direct contact with the electron-opaque matrix component (Figs. 10, 11), and ladder-like connection structures existed occasionally between both components (Figs. 11, 38, 41). In areas of direct contact with the electron-transparent lacunae, however, the extrahaustorial membrane usually showed undulations extending into the cytoplasm (Figs. 10 and 11, also visible in Figs. 4 and 42). Cisternae of endoplasmic reticulum, mitochondria, and Golgi bodies were frequently present in the host cytoplasm next to the haustoria (Figs. 2, 9, 12). Golgi bodies were normally orientated to the matrix profile with their peripheral regions (Figs. 2, 9, 12). Cisternae of endoplasmic reticulum were frequently found in intimate contact with the extrahaustorial membrane extending from the cytoplasm to the membrane and then following the membrane contours closely (Figs. 12-14). In addition, at the contact areas they were devoid of ribosomes, and small connection filaments of poor contrast were often arranged in a more or less regular spacing (Figs. 12-14). In few cases the matrix was encased partly at the haustorial flanks or completely by appositional material (Figs. 4, 9). Material resembled host cell wall and was continuous with it (Fig. 9). In some of these cases the matrix appeared thinner and only a few matrix vesicles were enclosed.

The tripartite nature of the membranes of the enclosed matrix vesicles was clearly recognizable after freeze substitution (Fig. 8) but not after conventional fixation (Fig. 7). As indicated by serial sections, in advanced haustorial stages the matrix vesicles were separated from both the fungus and the host (Figs. 4, 6, 9, serial sections not illustrated). Though distributed throughout the matrix (Fig. 4), their numbers varied from haustorium to haustorium. Matrix vesicles were highly branched with many lobes that gave the vesicles a coralloid appearance (Fig. 8). A very thin electron-transparent line followed the contours of vesicle membranes closely (Figs. 6-8). In older interaction stages the matrix vesicles were frequently collapsed (not illustrated).

\section{Fungal development}

In the initial stages of interaction, the fungal wall was very thin at the contact area with the host cell wall, and difficult to distinguish from the host cell wall after freeze substitution (Figs. 15-18) and conventional fixation (Figs. 25-28). During the contact phase of the hypha with the host cell wall the matrix began to develop and appeared at the host side between host cell wall and host plasma membrane (Figs. 15, 18). Development continued during the penetration process (Figs. 16, 17) and after penetration at the haustorial tips during haustorial growth (Figs. 19, 20). The penetration hypha thus first came in contact with the matrix after penetration. It never had direct contact with the host plasma extrahaustorial membrane.

Material corresponding to the electron-opaque matrix material was not found in the cytoplasm of host cells in contact with penetration hyphae. During development of the matrix, two different types of vesicle complexes were located in the hyphal tips (Figs. 15, 17, 18). The first type was observed only in the regions of interaction and consisted of vesicles and straight tubules with electron-opaque contents that corresponded to the densely stained material of the matrix (Figs. 15, 21-23). Tubules showed usually one or several margin bulgings and buds at one or both ends, indicating formation of the vesicles (Figs. 21, 22). Compared with the appearance after freeze substitution, after conventional fixation the vesicle complex was typically altered: like the 
Figs. 9-14. Host characteristics around haustoria prepared by freeze substitution. Fig. 9. The matrix surrounding the haustorium $(h)$ is encased by appositional material (arrows) which is continuous with the host cell wall (arrowhead). Golgi bodies, cisternae of endoplasmic reticulum, and mitochondria are neighboured. Note the unusual orientation of the Golgi body to the haustorium. Scale bar $=0.5 \mu \mathrm{m}$. Figs. 10 and 11 . At the points of direct contact to the electron-opaque matrix material $(m)$ the extrahaustorial membrane appears smooth (arrowheads), whereas at the other areas it has an undulating topography. In Fig. 11 ladder-like connections extend between the matrix and the extrahaustorial membrane (arrows). Note the coated membrane in Fig. 10 at arrow. Scale bar $=0.5 \mu \mathrm{m}$ in Fig. 10 and $0.1 \mu \mathrm{m}$ in Fig. 11. Fig. 12. Mitochondrion (M), Golgi body (D), cisterna of endoplasmic reticulum (ER), and coated vesicle (large arrowhead) in close proximity to the extrahaustorial membrane (arrow). The cisterna extends from the cytoplasm to the extrahaustorial membrane and then follows the contour of the membrane closely. At the contact area with the extrahaustorial membrane it is devoid of ribosomes and fine lines exist between both (small arrowheads). Note that the Golgi cisternae are oriented with their peripheral regions to the matrix. Note also the equal layering of extrahaustorial membrane. Scale bar $=0.1 \mu \mathrm{m}$. Fig. 13. Cisterna of endoplasmic reticulum (ER) with numerous ribosomes extends from the cytoplasm to the extrahaustorial membrane (arrow). Ribosomes are absent at the contact area. Scale bar $=0.1 \mu \mathrm{m}$. Fig. 14. Fine filaments (arrowheads) are seen between the extrahaustorial membrane (arrow) and the intimately associated cisterna of endoplasmic reticulum (ER). Ribosomes are absent in this area. Scale bar $=0.1 \mu \mathrm{m}$.

Figs. 15-20. Contact and penetration phase prepared by freeze substitution. Scale bars $=0.5 \mu \mathrm{m}$. Fig. 15. Intercellular hypha (ih) contacting host cell wall (HW). Matrix material $(m)$ is deposited between host cell wall (HW) and host plasma membrane. The first vesicular buds are evident (arrow). Numerous vesicles containing electron-opaque contents (vesicle complex 1) accumulate at the hyphal tip. Note that the fungal cell wall $(f w)$ is difficult to distinguish from the host cell wall (HW). Fig. 16. Intercellular hypha (ih) lodged in the host cell wall (HW). A cisternal bud of a Golgi body (arrow) is seen in intimate contact with the matrix ( $m$ ). Fig. 17. Intercellular hypha $(\mathrm{ih})$ penetrating host cell wall $(\mathrm{HW})$. Behind the area of vesicle complex 1 a second vesicle complex (type 2 ) is visible within the penetration dome. Note the young matrix $(m)$. Fig. 18. Intercellular hypha (ih) contacting host cell wall (HW). Vesicle complex 2 is positioned next to the hyphal tip. The fungal and host cell wall are more or less indistinguishable from each other. Note the young matrix $(m)$ and the vesicular bud in the host plasma membrane (arrow). Figs. 19 and 20. Interaction stages after penetration. Each hypha (ih) contacts the matrix and the fungal cell wall appears clearer than in penetration stages.

electron-opaque matrix material itself, the densely stained contents of the vesicles and tubules were more concentrated and were separated from the vesicle-tubule membrane by an electron-transparent, unstructured sheath (Fig. 24). The vesicles were seen in close contact with the fungal plasma membrane at the hyphal tip, suggesting exocytosis (Figs. 15, $17,21)$. In addition, fusion and secretion profiles were present (Figs. 21, 28).

Deposition of electron-opaque material between host plasma membrane and host cell wall was associated with a change in the structure of the host cell wall in the region of interaction. This change appeared much more distinct in conventionally fixed material (Figs. 25-28) than in freeze-substituted material (Figs. 29, 30), especially in thick host cell walls (Figs. 25-28). The change was visible as a granular increase in the electron opacity of the host cell wall starting from the hyphal tip (Fig. 25) and extending through the host cell wall towards the host plasma membrane (Figs. 26, 27). Subsequently, electron-opaque granules became deposited between host cell wall and host plasma membrane exactly at the ends of the altered areas in the host cell wall (Figs. 26, 27). The host plasma membrane was intimately attached to the electron opaque granules, whereas it was undulated between them (Figs. 26, 27). Deposition of electron-opaque material then continued (Fig. 28) to form the matrix. In all stages observed the young matrix was not encased by a secondary wall layer of the host of collar material.

The second vesicle complex seen in the tip of the penetration hypha (Figs. 17, 18) also was found in the tips of intercellular hyphae that were not in contact with host cells. It consisted of electron-transparent, variously shaped segments that were irregular, ringed, and curved with extensions or agglomerations (Figs. 31-34). The two different vesicle complexes were often found adjacent to each other but were never in direct contact (Fig. 17). In addition, in the apical penetration dome either the first vesicle complex was centrally positioned and the other type was neighboured or vice versa (Figs. 17, 18).

\section{Host response}

Host response to penetration and haustorial growth followed a defined pattern. Beginning with the contact and penetration phase and continuing during haustorial growth at the haustorial tips, vesicular buds arose from the host plasma membrane around the matrix extending into the matrix (Figs. 15, 18, 40, 41). There seemed to be a regular spacing of the buds. Initially they were more or less globular in shape, and later they elongated and formed many coralloid branches (Figs. 40-45). The membranes of the vesicular buds were continuous with the host plasma - extrahaustorial membrane (Figs. 40-45). The inner space was organelle free, including ribosomes, and was filled with material of greater electron opacity than the adjacent cytoplasm areas (Figs. 40-45). Bud openings were sometimes occluded by cisternae of endoplasmic reticulum (Fig. 45). Additionally, cisternae were seen extending into the inner space of the buds (Fig. 42). A fine electron-transparent line normally followed closely the contours of these buds (Figs. 40-44). Morphology of the coralloid buds was essentially identical to that of the vesicles completely enclosed within the matrix (compare Fig. 41 with Fig. 8). In haustorial stages the vesicular buds in the extrahaustorial membrane were present around the haustorial tips, whereas at the haustorial flanks towards the haustorial base they were increasingly substituted by coralloid matrix vesicles that were completely separated from the extrahaustorial membrane (serial sections not illustrated).

Many Golgi bodies and vesicles were located around the developing matrix (Figs, 16, 35-39). Golgi bodies were 

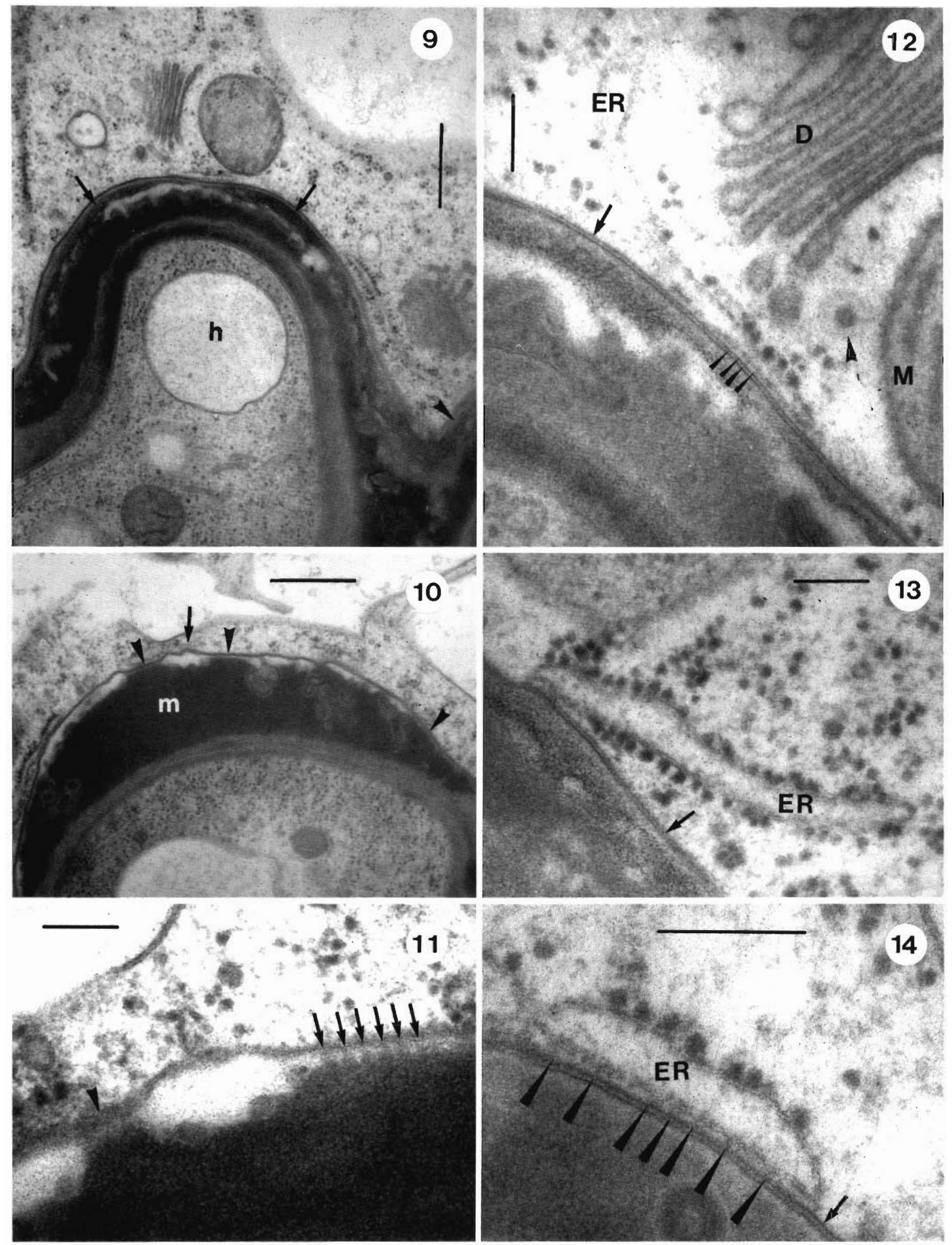


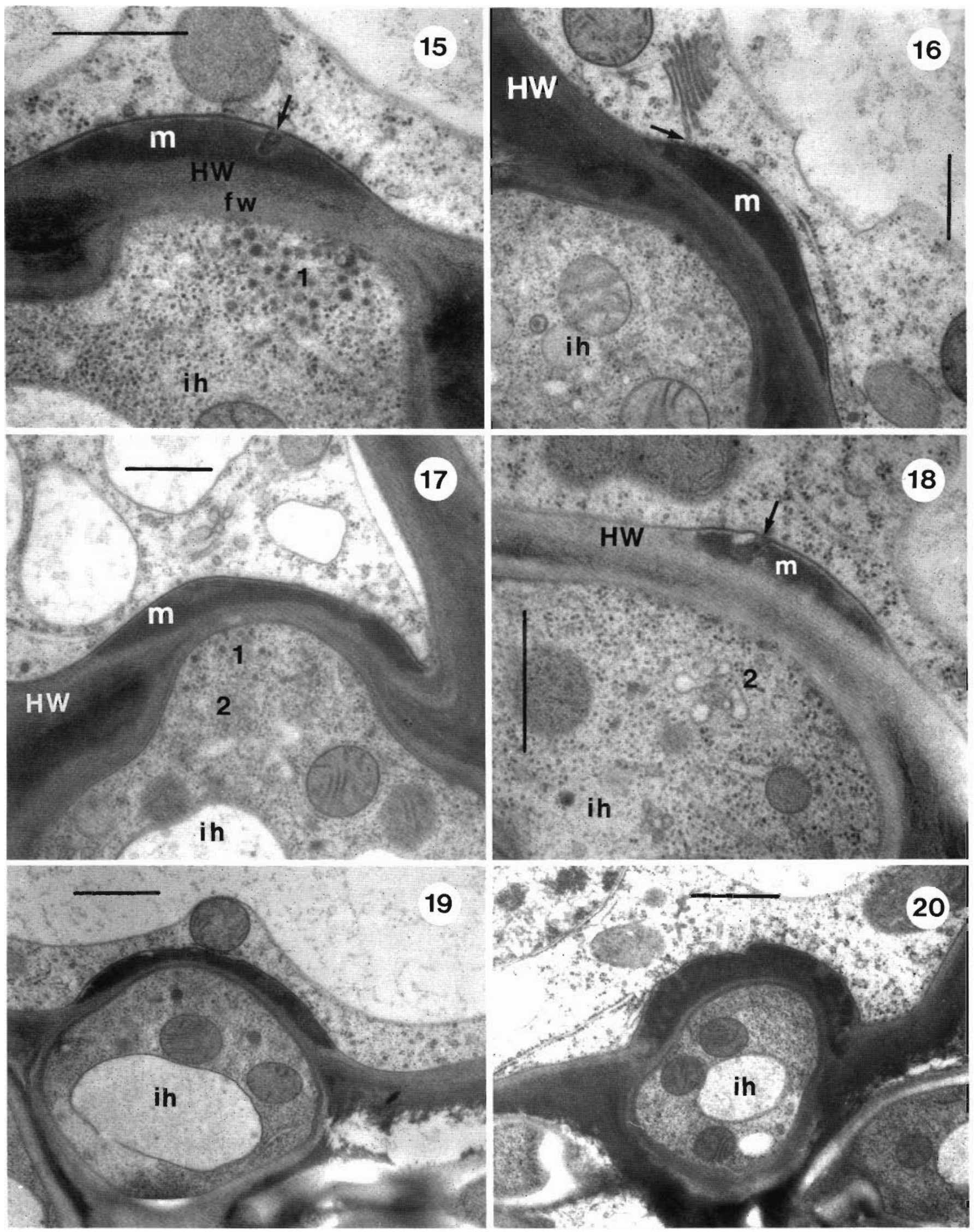


Figs. 21-24. Vesicle complex 1 prepared by freeze substitution (Figs. $21-23$ ) or conventional fixation (Fig. 24). Scale bars = $0.1 \mu \mathrm{m}$. Fig. 21. Vesicle complex 1 is closely associated to the fungal plasma membrane, indicating exocytosis. One tubule with some buds at one end (arrowheads). Note the fusion profile of one vesicle (arrow). Fig. 22. Section showing a tubule with buds at both ends. Note the associated vesicle (arrow). Fig. 23. Section showing the tripartite nature of the vesicle membranes (arrowheads). Fig. 24. Typical appearance of the vesicle complex 1 after conventional fixation. The electron-opaque contents of the vesicles (arrowheads) and the tubule (arrow) are more concentrated than after freeze substitution (compare with Fig. 23) and surrounded by an unstructured sheath. Note the two buds on the tubule.
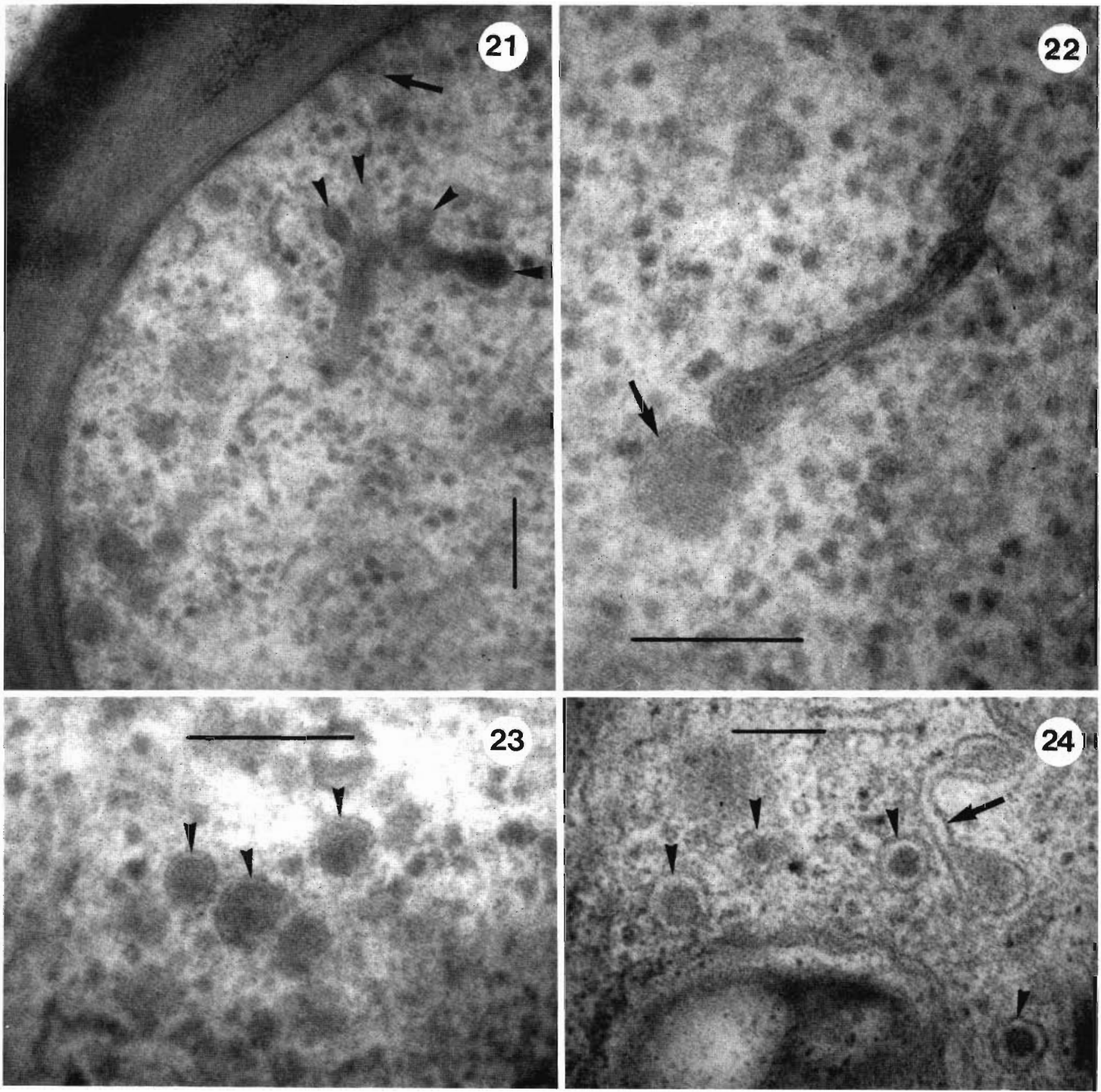

normally orientated to the profile of the matrix with their peripheral regions and not with their cis or trans sides (Figs. 16, 35-39). They were without any forms of tubularvesicular network. Numerous Golgi vesicles were closely associated with the host plasma - extrahaustorial membrane (Figs. 35, 37, 43-45); they were frequently positioned in

the bud openings (Figs. 36, 37, 43, 44) and in the inner spaces of the vesicular buds (Fig. 45). In addition, fusion profiles at the host plasma membrane or within the buds (Fig. 45) were found several times. In several cases smal] lines were observed between the host plasma membrane and intimately associated Golgi vesicles extending from the inner 


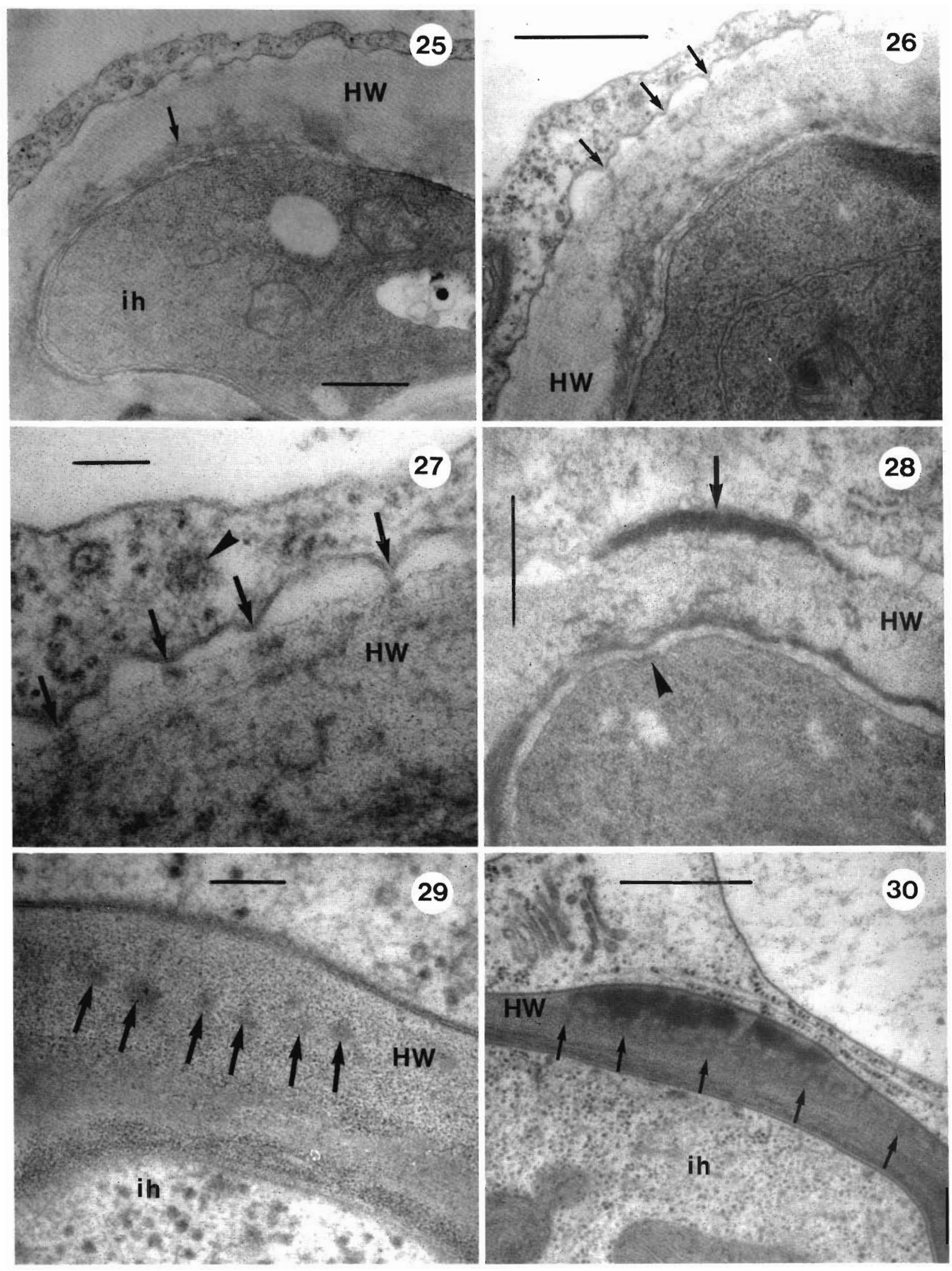


Figs. 25-30. Matrix development by transfer of fungal material through the host cell wall (HW) prepared by conventional fixation (Figs. 25-28) or freeze substitution (Figs. 29, 30). Fig. 25. Intercellular hypha (ih) contacting host cell wall (HW). Initial stage of transfer. Electron-opaque material (arrow) infiltrates the host cell wall starting from the intercellular hypha and extending through the host cell wall. Scale bar $=0.5 \mu \mathrm{m}$. Fig. 26. The first material granules have reached the host plasma membrane (arrows). Note the undulating topography of the host plasma membrane between the contact points. Scale bar $=0.5 \mu \mathrm{m}$. Fig. 27. Detail from Fig. 26 illustrated to show the infiltration of the host cell wall $(\mathrm{HW})$ by material flocks. The first material flocks contact the host plasma membrane (arrows), which is invaginated between the points of contact. Note the coated vesicle (arrowhead). Scale bar $=$ $0.1 \mu \mathrm{m}$. Fig. 28. As the transfer continues, the first material accumulates (arrow) between the host cell wall (HW) and the host plasma membrane to form the matrix. Note the secretion profile at the hyphal tip (arrowhead). Scale bar $=0.5 \mu \mathrm{m}$. Fig. 29 . Intercellular hypha $(\mathrm{ih})$ contacting host cell wall $(\mathrm{HW})$ after freeze substitution. Material flocks within the host cell wall are seen at arrows. Scale bar $=0.1 \mu \mathrm{m}$. Fig. 30. Similar developmental stage after freeze substitution as illustrated in Fig. 28 for conventional fixation. The extrahaustorial begins to develop and the host cell wall (HW) is still infiltrated by electron-opaque material (arrows). Note that the transfer is more distinct after conventional fixation than after freeze substitution. Intercellular hypha is visible at $i h$. Scale bar $=0.5 \mu \mathrm{m}$.

Fig. 31-34. Vesicle complex 2 prepared by freeze substitution. Scale bars $=0.1 \mu \mathrm{m}$. Sections showing the different shapes of vesicle complex 2: irregular (Fig. 31), ringed (Fig. 32), ringed with extension into the cytoplasm (Fig. 33), or agglomeration (Fig. 34).
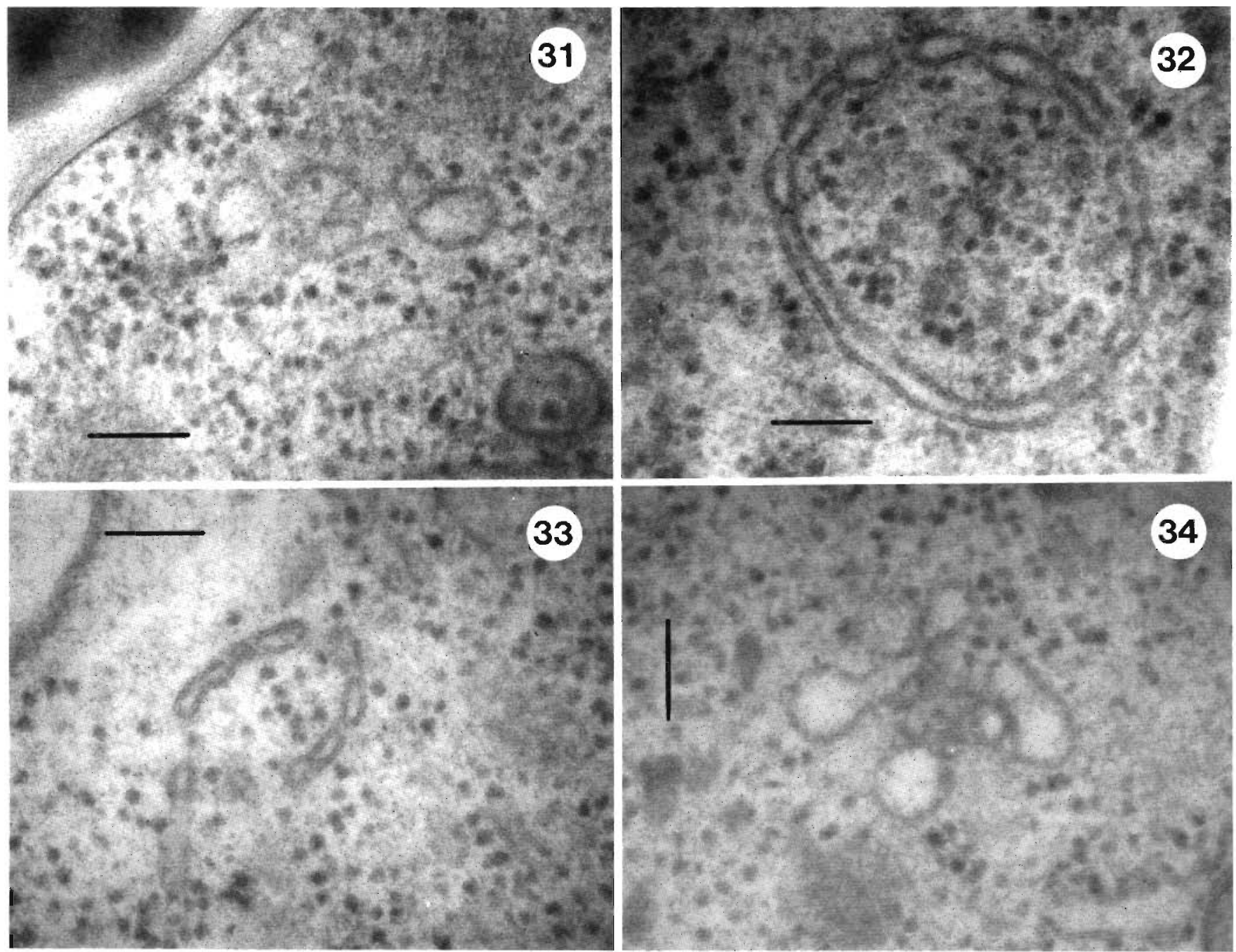

electron-opaque layer of the vesicle membrane (Fig. 44). Golgi bodies sometimes were present in close contact with the host plasma membrane. In such cases buds at the cisternal peripheries appeared to interact directly with the host plasma membrane (Figs. 16, 38). In addition, as indicated by serial sections, different median cisternae of a single Golgi body seemed to feed different exocytosis points (Figs. 37-39).

Whereas exocytotic stages were numerous, only a few 
Figs. 40-45. Vesicular buds at the host plasma - extrahaustorial membrane in different developmental stages prepared by freeze substitution. The matrix is visible at $m$. Scale bars $=0.1 \mu \mathrm{m}$. Fig. 40 . Section through three vesicular buds. One medianly sectioned bud showing the continuity of the bud membrane with the host plasma membrane (arrow). Fig. 41 . Section through a nearly mature, highly branched vesicular bud. Note the connection structures (arrowheads) between the matrix $(m)$ and the host plasma membrane at one side of the bud. Fig. 42. A cisterna of endoplasmic reticulum follows the contours of the matrix $(\mathrm{m})$ and extends into the inner space of a vesicular bud (arrow). Fig. 43. Detail from Fig. 37 showing a Golgi vesicle (arrow) in the opening of a vesicular bud. Also visible is a second vesicle, probably hastening towards the same bud (arrowhead). $m$, matrix. Fig. 44. Two Golgi vesicles intimately associated with the matrix $(m)$. The right vesicle enters the inner space of a developing vesicular bud. The left vesicle seems to be connected with the host plasma membrane by fine lines (arrowheads). Note the further neighboured Golgi vesicles. Fig. 45. Two Golgi vesicles intimately associated with the matrix $(m)$. The lower vesicle situated within the inner space of the bud showing a fusion profile (arrowhead). Note that a cisterna of endoplasmic reticulum (ER) occludes the opening of the bud.

Figs. 35-39. Relationship of Golgi bodies and Golgi vesicles to the matrix $(m)$ in overviews prepared by freeze substitution. Scale bars $=0.1 \mu \mathrm{m}$. Fig. 35. Haustorial tip in cross section through the matrix $(\mathrm{m})$ showing many Golgi bodies and Golgi vesicles around the matrix. Fig. 36. In extension of the long plane of the Golgi cisternae a Golgi vesicle enters the inner space of a vesicular bud (arrowhead). $m$, matrix. Figs. 37-39. Sections 1, 4, and 5 from a series through a Golgi body interacting with the matrix $(m)$ showing three of five interaction sites observed in the series $(1,2,3)$. In Fig. 38 ladder-like connections (arrowhead) are present between the matrix $(m)$ and the host plasma membrane. Note the intimate contact of the cisternal bud with the host plasma membrane in Fig. 38 at 2 . The series represent the same interaction stage as illustrated in Fig. 16.
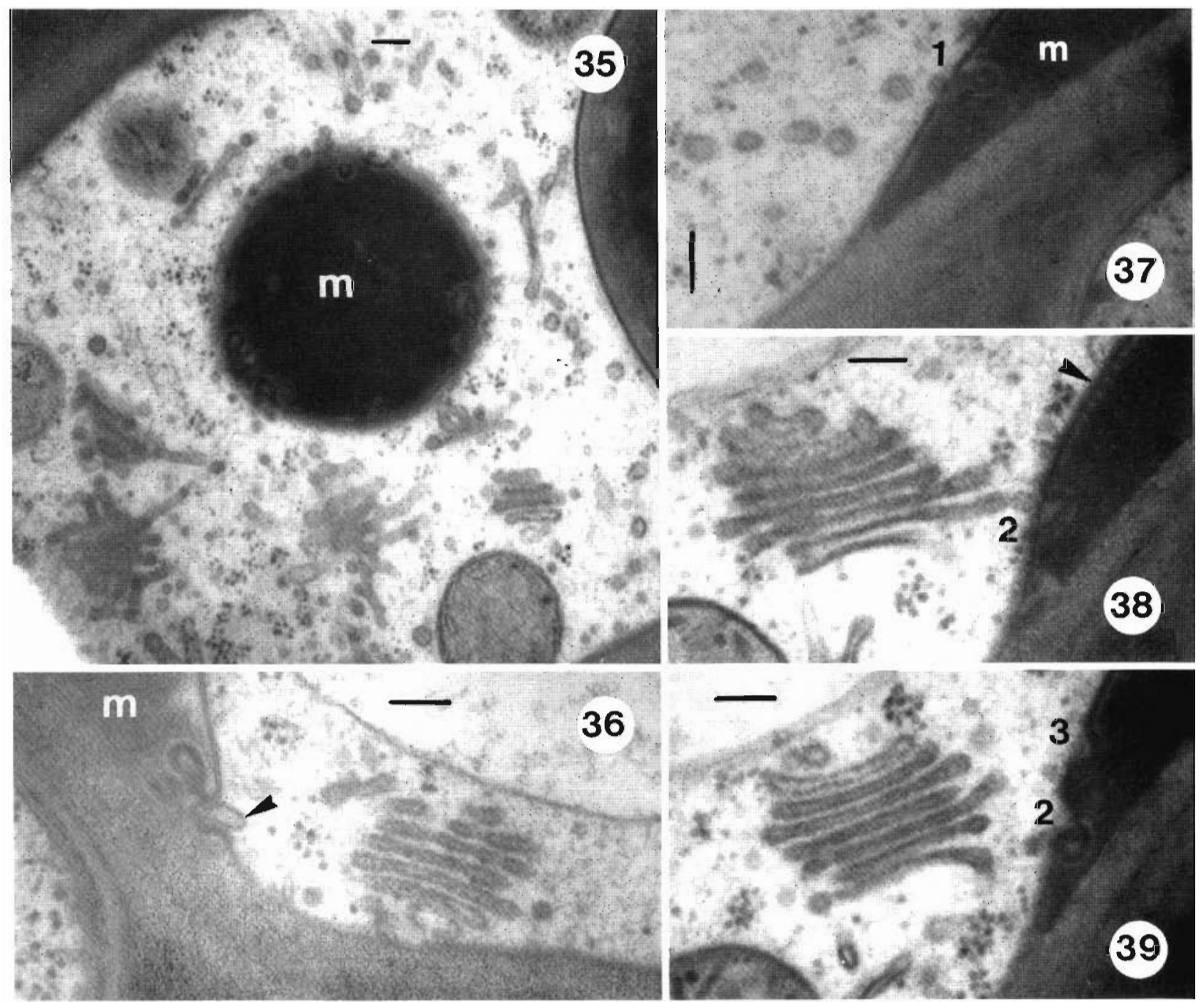

endocytotic stages were visualized. Furthermore, coated membranes - pits - vesicles were found only in areas of the host plasma - extrahaustorial membrane that were separated

from the matrix material by an electron-transparent zone (Figs. 10 and 46-48). Between Golgi bodies and the host plasma membrane the coated vesicles usually were associated 


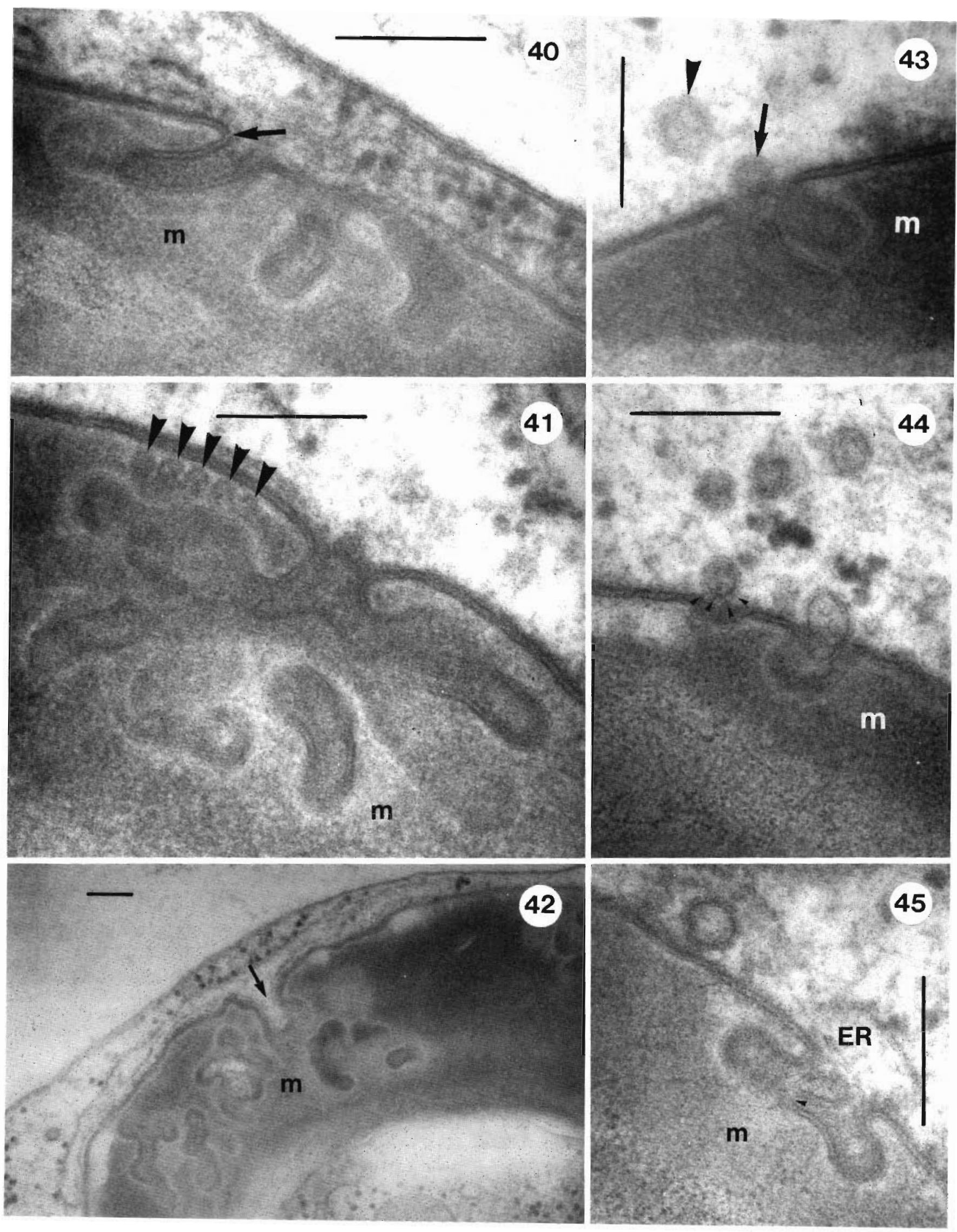


Figs. 46-49. Exocytosis of host cells responding to infection prepared by freeze substitution. Scale bars $=0.1 \mu \mathrm{m}$. Figs. 46 and 47 . Coated pits are present in the extrahaustorial membrane (arrowheads). Note the absence of electron-opaque matrix material at these regions. Fig. 48. A coated vesicle (arrowhead) situated next to the matrix $(m)$. Note the invagination of the extrahaustorial membrane and the absence of the electron-opaque matrix material at this point. Fig. 49. Section showing a coated vesicle in intimate contact with a microtubule. The matrix is visible at $m$.
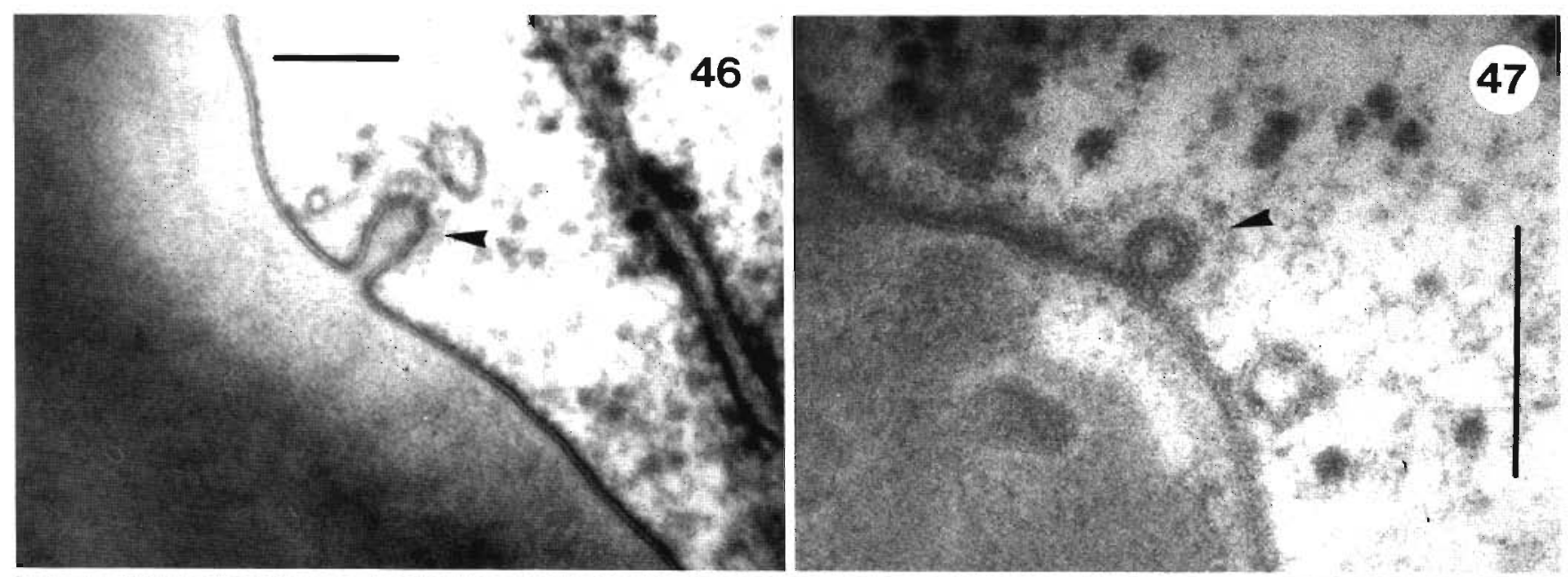

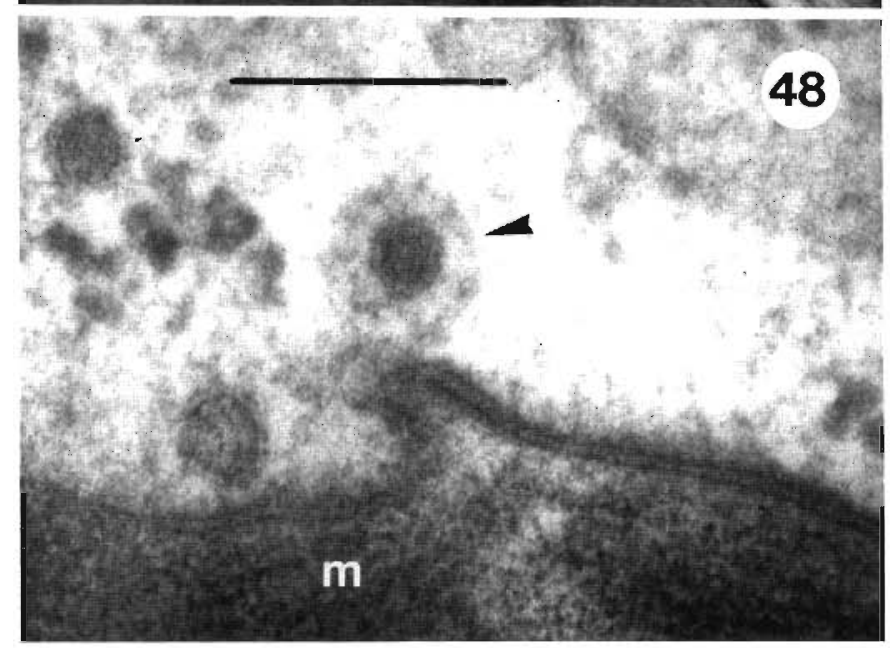

with microtubules (Fig. 49). Some coated vesicles were found in close proximity to Golgi bodies (Fig. 12).

\section{Discussion}

\section{General observations}

It was necessary to add $6 \%$ methanol to the infiltration fluid prior to high-pressure freezing to suppress detectable effects of ice crystal formation. However, the comparison of the freeze-substituted and conventionally fixed interaction stages indicates that the use of $6 \%$ methanol had no deleterious effect on the fine structure of the samples: the differences between the freeze-substituted and conventionally fixed interaction stages observed in this study reflect only the general differences between freeze substitution and chemical fixation, as described and illustrated by many authors (e.g., Hoch and Howard 1980; Hoch and Staples 1983; Hoch 1986; Berbee and Wells 1988; Mims et al. 1988; Welter et al. 1988; Berbee et al. 1991).

\section{Functional aspects}

Although it is not possible from electron micrographs to determine directly the development and the vesicle flow, the

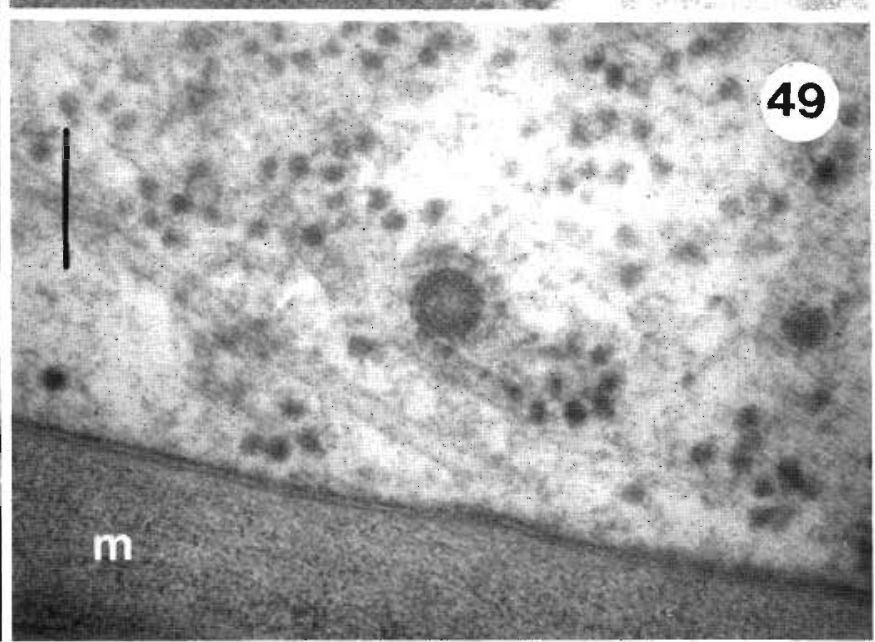

comparison of many and especially different developmental stages permits their arrangement in a logical and plausible series. By doing so, the cellular interaction between Ustacystis waldsteiniae and $W$. geoides reveals an orchestrated pattern of events.

Initial stages of interaction in Ustacystis waldsteiniae are basically similar to those illustrated for the downy mildews Peronospora pisi Sydow (Hickey and Coffey 1977), Phytophthora infestans (de Bary) Mont. (Coffey and Wilson 1983), and especially Phytophthora cinnamomi Rands (Wetherbee et al. 1985). The similarities include the presence of densely stained vesicles at the penetration region, the localized increase in the electron opacity of the host cell wall, and the deposition of electron-opaque material between host cell wall and host plasma membrane (Wetherbee et al. 1985). Wetherbee et al. (1985) hypothesized that a primary fungus signal makes contact with a complementary host wall component. This contact results in production of a secondary signal that activates plasma membrane associated enzymes of the host for deposition of electron-dense core material. The details observed in our study indicate, however, that in the interaction of Ustacystis waldsteiniae with $W$. geoides, the electron-opaque matrix material is, at least partly, of fungal origin, deriving directly 
from the vesicle material by transfer through the host cell wall. A vesicle complex containing electron-opaque material appears at the hyphal tip where the vesicles fuse with the plasma membrane and extrude their contents. Subsequently, the host wall increases in electron opacity and electronopaque granules become deposited between host cell wall and host plasma membrane to form the matrix. Thus, the changes in the structure of the host cell wall may reflect transfer stages. Fungal products in the matrix have been immunologically detected in the interaction of the anthracnose pathogen Colletotrichum lindemuthianum (O'Connell et al. 1986). In addition, both the matrix material and the content of the vesicles are more concentrated after conventional fixation than after freeze substitution. Obviously, they contract artificially during conventional fixation or vice versa. This presumed artifact of the conventional fixation together with the electron-transparent appearance of thick host cell walls after conventional fixation may be the reason why the transfer of material through the host cell wall appears much more distinct in conventionally fixed samples than in freeze-substituted samples, especially in thick host cell walls.

The second vesicle complex seen in the tip of the penetration hypha may represent the Golgi equivalent observed in many ascomycetes and basidiomycetes (see Mendgen et al. 1995).

In the host cell, vesicular buds then are induced to differentiate in response to matrix development from the host plasma - extrahaustorial membrane extending into the matrix. During their ontogeny, they become highly branched and finally they apparently separate from the host cytoplasm. This situation is unique among the various fungal plant parasites investigated so far (see Mims 1991 and the references therein). Several mechanisms may be integrated in this process. Exocytosis certainly creates the surplus of membranes that is necessary for the formation of the vesicular buds. Exocytosis alone, however, cannot explain the formation of the vesicular buds. Thus, it is surprising that this surplus remains stable in the form of the vesicular buds, although the surface of the host plasma membrane increases during haustorial growth. In addition, the bulging of the vesicular buds into the matrix is unusual. Some of our results lead us to suggest that the electron-opaque matrix material plays a dominant role in the formation of the buds: it appears to stabilize and bind the host plasma membrane. Thus, the host plasma membrane is smooth in the regions of direct contact with the electron-opaque matrix material, whereas it usually shows undulating topography in the other regions. In addition, in initial stages of matrix development the host plasma membrane is intimately attached to the matrix granules, whereas it is undulated between them. These invaginations may be artifacts of the conventional fixation, but they reveal one possible function of the material: to bind the host plasma - extrahaustorial membrane. The matrix material thus may prevent both the smoothness of the host plasma membrane during haustorial growth and the membrane recycling via endocytosis. This interpretation could explain our observation that the few coated pits-vesicles observed are located only in areas in which the matrix material is separated from the host plasma membrane by an electron-transparent zone and are never seen located in the inner space of the vesicular buds

In summary, the following scenario may be plausible and logical for the formation of the vesicular buds: matrix material binds and stabilizes the associated host plasma membrane and thus prevents membrane recycling via endocytosis. Vesicles released from Golgi bodies are transported to the host plasma membrane - vesicular buds where they fuse with the host plasma membrane and extrude their contents into the matrix. The extrusion of the Golgi products then results in the separation of the matrix from the host plasma membrane for a short time at the fusion site. The turgor pressure of the host cell simultaneously forces the inputted membrane to bulge into the matrix. During the bulging phase the bulging membrane comes in contact with the matrix material and becomes stabilized. Membrane recycling thus is prevented and the vesicular bud remains stable.

\section{Fungal advantages}

In this interaction three features appear to be advantageous for the parasite. (i) The Golgi products extruded via exocytosis could serve as direct nutriment for the parasite. This speculation is supported by the fact that the extrusion of Golgi products does not result in deposition of appositional material around the vesicular buds or the matrix. In contrast, in the few cases observed in which the matrix is encased by appositional material, the number of enclosed matrix vesicles is low. (ii) Exocytosis of Golgi products into the matrix results in the formation of coralloid vesicular buds in the host plasma - extrahaustorial membrane. At this stage the contact zone of the host cell resembles in some characteristics that of transfer cells (Gunning and Pate 1969). The structural similarities are the greatly increased surface to volume ratio at the contact zone and the associated ER. As discussed above, however, in the host cells responding to infection with Ustacystis waldsteiniae the increase of the surface to volume ratio is achieved by the formation of vesicular buds extending into the matrix, whereas in transfer cells it is achieved by wall ingrowths (Gunning and Pate 1969). Transfer cells have been documented in a wide variety of anatomical structures within bryophytes and higher plants (Gunning and Pate 1969; Hebant 1975; Wiencke and Schultz 1975; Browning and Gunning 1977). As described by Kottke and Oberwinkler (1987), organization of the ectomycorrhizal Hartig net also shows some features in common with transfer cells. Transfer cells are frequently associated with transport systems, and the increased surface area augments the transmembrane transport of solutes (Gunning and Pate 1969; Pate and Gunning 1972). Histochemical studies have shown that transfer cells are the site of intensive enzymatic activities, especially of phosphatases and respiratory enzymes (Hebant and Suire 1974). Thus, the host cells responding to infection with Ustacystis waldsteiniae become very well prepared for nutrient and solute transport. The data of our study indicate, however, that the transfer situation is involved in a dynamic process. The fact that in haustorial stages the vesicular buds around the haustorial tip are increasingly substituted by completely enclosed matrix vesicles towards the haustorial base may reflect the direction of development and the dynamic process. Development of new vesicular buds around the haustorial tip during haustorial growth and separation of presumed old buds around the haustorial flank are probably simultaneous processes. (iii) The host cell loses part of its cytoplasm by the separation of the vesicular buds from the host plasma - extrahaustorial membrane. The content of these enclosed matrix vesicles could also serve as direct 
nutriment for the parasite. At least the enclosed matrix vesicles seem to collapse with age.

\section{Phylogenetic aspects}

As reviewed by Mims (1991), fungal plant parasites interact quite differently with their hosts at the ultrastructural level. The similarities in initial stages of interaction between Ustacystis waldsteiniae and members of the downy mildews (Hickey and Coffey 1977; Coffey and Wilson 1983; Wetherbee et al. 1985) may be the result of convergent evolution. As in Ustacystis waldsteiniae, the haustoria of members of the downy mildews and some other parasites, such as Cercosporidium personatum (Mims et al. 1989), are usually encased by a prominent electron-opaque matrix. The matrix in the interaction of Ustacystis waldsteiniae and $W$. geoides, however, is a highly complex structure differing significantly from that found in these phytopathogenic fungi. The type of transfer cell-like compartments in the host cell and the resulting vesicular matrix makes the interaction between Ustacystis waldsteiniae and $W$. geoides unique.

In basidiomycetes, rust haustoria have been studied most extensively at the ultrastructural level (Littlefield and Heath 1979; see Mendgen and Deising 1993 and the references therein), but in this respect the smut fungi are insufficiently examined. Macrocyclic rust fungi produce two distinctively different types of haustoria depending upon the nuclear condition, but the characteristics of each type are basically homogeneous among the rust taxa. In contrast with the rust fungi, the few results existing from smut fungi suggest that smut fungi exhibit a diversity of interactions with host cells. For example, the mycelium of Tilletia caries (DC.) Tul. is almost entirely intercellular (Luttrell 1987), whereas Entorrhiza casparyana (P. Magnus) Lagerheim grows into the host cell and forms intracellular teliospores (Deml and Oberwinkler 1981). Others, such as Ustilago esculenta P. Hennings (Nagler et al. 1990), Ustilago striiformis (West.) Niessl. (Mims et al. 1992), Ustilago maydis (DC.) Corda, Ustilago nuda (Jens.) Rostr., Tolyposporium penicillariae Brefeld (Luttrell 1987; Snetselaar and Mims 1994), and Sorosporium provinciale (Ell. and Gall.) Clint. (Snetselaar and Tiffany 1990), grow indiscriminately both between, as well as into, and often through host cells. Urocystis spp. (Nagler and Oberwinkler 1989), like Ustacystis waldsteiniae, produce haustoria that always end in the host cell. The haustorial morphology and especially the structure of the haustorial interface of Ustacystis waldsteiniae resemble those of species of Urocystis, except that Urocystis haustoria possess usually more and longer lobes than Ustacystis haustoria. Ustacystis and Urocystis are further united in sharing a unique septal pore apparatus (Bauer et al. 1995). Thus, both genera may belong to a monophyletic group that is ultrastructurally characterized by haustoria with a vesicular interface and a simple septal pore apparatus with two bands and two membranous caps.

Interestingly, as in Urocystis and Ustacystis, the hostparasite interface in the phragmobasidiate smut fungi on grasses discussed above is filled with electron-opaque material. Perhaps this material is homologous to that of Ustacystis and Urocystis, reflecting a common apomorphy of these taxa, but additional studies are needed to clarify this supposition.

\section{Acknowledgments}

We thank Professor Charles W. Mims, Dr. Reinhard Berndt, and Dr. Meike Piepenbring for critically reading the manuscript, Annette Klink and Sabine Silberhorn for excellent technical assistance, and the Deutsche Forschungsgemeinschaft for financial support.

\section{References}

Bauer, R., Berbee, M.L., and Oberwinkler, F. 1991. An electron microscopic study of meiosis and the spindle pole body cycle in the smut fungus Sphacelotheca polygoni-serrulati. Can. J. Bot. 69: 245-255.

Bauer, R., Mendgen, K., and Oberwinkler, F. 1995. Septal pore apparatus of the smut Ustacystis waldsteiniae. Mycologia, 87: 18-24.

Berbee, M.L., and Wells, K. 1988. Ultrastructural studies of mitosis and septal pore apparatus in Tremella globospora. Mycologia, 80: 479-492.

Berbee, M.L., Bauer, R., and Oberwinkler, F. 1991. The spindle pole body cycle, meiosis, and basidial cytology of the smut fungus Microbotryum violaceum. Can. J. Bot. 69: 1795-1803.

Browning, A.J., and Gunning, B.E. 1977. An ultrastructural and cytochemical study of the wall-membrane apparatus of transfer cells using freeze substitution. Protoplasma, 93: 7-26.

Bushnell, W.R. 1972. Physiology of fungal haustoria. Annu. Rev. Phytopathol. 10: 151-176.

Coffey, M.C., and Wilson, U.E. 1983. An ultrastructural study of the late-blight fungus Phytophthora infestans and its interaction with the foliage of two potato cultivars possessing different levels of general (field) resistance. Can. J. Bot. 61: 2669-2685.

Deml, G., and Oberwinkler, F. 1981. Investigations on Entorrhiza casparyana by light and electron microscopy. Mycologia, 73: 392-398.

Gunning, B.E., and Pate, J.S. 1969. "Transfer cells" plant cells with wall ingrowths specialized in relation to short distance transport of solutes-their occurrence, structure and development. Protoplasma, 68: 107-133.

Hebant, C. 1975. Organization of the conducting tissue-system in the sporophytes of Dawsonia and Dendroligotrichum. J. Hattori Bot. Lab. 39: 235-254.

Hebant, C., and Suire, C.L. 1974. Mise en évidence d'activités enzymatiques au niveau de la zone de transfert gamétophyto-sporophyte chez quelques bryophytes. Rev. Bryol. Lichenol. 40: 171-181.

Hickey, E.L., and Coffey, M.D. 1977. A fine-structural study of the pea downy mildew fungus Peronospora pisi in its host Pisum sativum. Can. J. Bot. 55: $2845-2858$.

Hoch, H.C. 1986. Freeze substitution of fungi. In Ultrastructure techniques for microorganisms. Edited by H.C. Aldrich and W.J. Todd. Plenum Publishing Corporation, New York. pp. 183-212.

Hoch, H.C., and Howard, R.J. 1980. Ultrastructure of freeze-substituted hyphae of the basidiomycete Laetisaria arvalis. Protoplasma, 103: 281-297. 
Hoch, H.C., and Staples, R.C. 1983. Ultrastructural organization of the nondifferentiated uredospore germling of Uromyces phaseoli variety typica. Mycologia, 75: 795-824.

Kottke, I., and Oberwinkler, F. 1987. Cellular structure and function of the Hartig net: coenocytic and transfer cell-like organization. Nord. J. Bot. 7: 85-95.

Littlefield, L.J., and Heath, M.C. 1979. Ultrastructure of rust fungi. Academic Press, New York.

Luttrell, E.S. 1987. Relations of hyphae to host cells in smut galls caused by species of Tilletia, Tolyposporium, and Ustilago. Can. J. Bot. 65: 2581-2591.

Mendgen, K., and Deising, H. 1993. Infection structures of fungal plant pathogens-a cytological and physiological evaluation. Tansley Review No. 48. New Phytol. 124: 193-213.

Mendgen, K., Welter, K., Scheffold, F., and Knauf-Beiter, G. 1991. High pressure freezing of rust infected plant leaves. In Electron microscopy of plant pathogens. Edited by K. Mendgen and D.E. Lesemann. Springer Verlag, Heidelberg, Germany. pp. 31-42.

Mendgen, K., Bachem, U., Stark-Urneau, M., and $\mathrm{Xu}, \mathrm{H} .1995$. Secretion and endocytosis at the interface of plants and fungi. Can. J. Bot. 73(Suppl.). In press.

Mims, C.W. 1991. Using electron microscopy to study plant pathogenic fungi. Mycologia, 83: 1-19.

Mims, C.W., Roberson, R.W., and Richardson, E.A. 1988. Ultrastructure of freeze-substituted and chemically fixed basidiospores of Gymnosporangium juniperi-virginianae. Mycologia, 80: 356-364.

Mims, C.W., Luttrell, E.S., and Aldermann, S.C. 1989. Ultrastructure of the haustorium of the peanut late leaf spot fungus Cercosporidium personatum. Can. J. Bot. 67: $1198-1202$.

Mims, C.W., Snetselaar, K.M., and Richardson, E.A. 1992. Ultrastructure of the leaf stripe smut fungus Ustilago strilformis: host-pathogen relationship and teliospore development. Int. J. Plant Sci. 153: $289-290$.

Nagler, A., and Oberwinkler, F. 1989. Haustoria in Urocystis (Tilletiales). Plant Syst. Evol. 165: 17-28.
Nagler, A., Bauer, R., Oberwinkler, F., and Tschen, J. 1990. Basidial development, spindle pole body, septal pore, and host-parasite interaction in Ustilago esculenta. Nord. J. Bot. 10: 457-464.

Oberwinkler, F. 1985. Zur Evolution und Systematik der Basidiomyceten. Bot. Jahrb. Syst. 107: $541-580$.

O'Connell, R.J., Bailey, J.A., Vose, I.R., and Lamb, S.J. 1986. Immunogold labelling of fungal antigens in cells of Phaseolus vulgaris infected by Colletotrichum lindemuthianum. Physiol. Plant Pathol. 28: 99-105.

Pate, J.S., and Gunning, B.E. 1972. Transfer cells. Annu. Rev. Plant Physiol. 23: 173-196.

Reynolds, E.S. 1963. The use of lead citrate at high $\mathrm{pH}$ as an electron opaque stain in electron microscopy. J. Cell Biol. 17: 208-212.

Snetselaar, K.M., and Mims, C.W. 1994. Light and electron microscopy of Ustilago maydis hyphae in maize. Mycol. Res. 98: 347-355.

Snetselaar, K.M., and Tiffany, L.H. 1990.' Light and electron microscopy of sorus development in Sorosporium provinciale, a smut of big bluestem. Mycologia, 82: $480-492$.

Spurr, A.R. 1969. A low-viscosity epoxy resin embedding medium for electron microscopy. J. Ultrastruct. Res. 26: $31-43$.

Vánky, K. 1987. Illustrated genera of smut fungi. Cryptogam. Stud. 1: 1-159.

Welter, K., Müller, M., and Mendgen, K. 1988. The hyphae of Uromyces appendiculatus within the leaf tissue after high pressure freezing and freeze substitution. Protoplasma, 147: $91-99$.

Wetherbee, R., Hinch, J.M., and Clarke, A.E. 1985. Response of Zea mays roots to infection with Phytophthora cinnamomi II. The cortex and stele. Protoplasma, 126: 188-197.

Wiencke, C., and Schultz, D. 1975. Sporophytenentwicklung von Funaria hygrometrica Sibth. I. Strukturelle Grundlagen der Wasser- und Nährstoffaufnahme im Haustorium. Protoplasma, 86: $107-117$. 